[18] Nguyen, M.-T., Peisl, L., Barletta, F., Luqman, A., Götz, F. (2018). Toll-Like Receptor 2 and Lipoprotein-Like Lipoproteins Enhance Staphylococcus aureus Invasion in Epithelial Cells. Infection and Immunity, 86 (8). doi: http://doi.org/10.1128/ iai.00627-18

[19] Xue, X., Qiu, Y., Jiang, D., Jin, T., Yan, M., Zhu, X., Chu, Y. (2017). The association analysis of TLR2 and TLR4 gene with tuberculosis in the Tibetan Chinese population. Oncotarget, 8 (68). doi: http://doi.org/10.18632/oncotarget.22996

[20] Zhao, J., Shang, H., Cao, X., Huang, Y., Fang, X., Zhang, S. et. al. (2017). Association of polymorphisms in TLR2 and TLR4 with asthma risk. Medicine, 96 (35), e7909. doi: http://doi.org/10.1097/md.0000000000007909

\title{
USE OF PLATELETS RICH PLASMA AS A FACTOR OF THE REDUCTION OF THE RISK OF EARLY POSTOPERATIVE COMPLICATIONS IN PATIENTS WITH POSTOPERATIVE VENTRAL HERNIAS
}

\author{
Dmitry Atanasov \\ Department of Surgery No. 4 with a course of oncology \\ Center for Reconstructive and Restorative Medicine (University Clinic) \\ Odessa National Medical University \\ 2 Valihovsky ave., Odessa, Ukraine, 65082 \\ dmitriyatanasov@gmail.com
}

\begin{abstract}
Non-tensioned allohernioplasty with a polypropylene mesh implant has several disadvantages associated with the local occurrence of non-specific long-lasting inflammatory reactions in response to a foreign body. Excessive exudation in the implantation zone leads to the formation of seromas, requiring puncture aspiration, which significantly increases the treatment time. In the longterm, chronic prolonged inflammatory process leads to the formation of coarse connective tissue, which explains the development of biomechanical complications. Growth factors, introduced by platelet rich plasma (PRP), stimulate the release of regenerative cytokines, reduce local inflammatory manifestations in the integration of homoplastic grafts and reduce the incidence of postoperative complications.

Aim: through the use of plasma enriched with platelets reduce the severity of early postoperative complications in patients with postoperative ventral hernias.

Materials and methods. A clinical study was performed in the surgical department of the center for reconstructive and restorative medicine (university clinic) of the Odessa National Medical University (ONMedU) in the period from 2013 to 2019 : 84 patients were operated because of postoperative ventral hernia. The average age of patients was $60.1 \pm 7.6$ years. The size of hernial defects was on average $8.2 \mathrm{~cm}$. The average BMI was $31.8 \mathrm{~kg} / \mathrm{m}^{2}$. According to indications, patients underwent a standard surgical extent of intervention: hernia repair, allohernioplasty of the anterior abdominal wall with a lightweight $(80 \mathrm{~g} / \mathrm{m} 2)$ polypropylene implant. After the plastics of the main group, a prosthesis implantation zone was infiltrated with activated autologous PRP, which was prepared by double centrifugation, in a volume of $14-38 \mathrm{ml}$. There was a control group in which PRP infiltration was not performed. The cavity above the mesh implant was actively drained by Redon for $2-4$ days. An ultrasound examination was performed and, if necessary, fine needle aspiration of serous fluid over the mesh was done.

Results. The evaluation of the postoperative period (up to 28 days) in patients of both groups. In none of the cases were manifestations of allergic, pyrogenic, local inflammatory or infectious complications. According to the quantitative assessment of early postoperative complications as well as the assessment of the degree of pain syndrome subjectively, according to VAS, the postoperative period in the main and control study groups was almost identical. The need for puncture aspirations and the total volume of discharge was significantly less in the main study group. The dependence of the severity of the effect of the proposed technology on such factors as the size of the hernial defect, the nature of plastics, and body mass index was noted. The greatest efficacy was demon-
\end{abstract}


strated in the group of patients undergoing plastic surgery with the placement of a mesh implant in direct contact with subcutaneous fatty tissue for large-sized hernias (W2+) in the presence of concomitant obesity.

Conclusions: the risk of development and the severity of fluid accumulations in the area of allohernioplasty can be predicted taking into account such risk factors as the size of the hernial defect, the nature of plastics, the presence of concomitant pathology, overweight. The technique of soft tissue infiltration in contact with a polypropylene prosthesis is safe, without significantly increasing the risk of local or systemic complications. The proposed method significantly reduces the risk of development and the severity of fluid accumulations in the area of implantation of the prosthesis. The effectiveness of technology is significantly higher compared to groups of patients with a high risk of seromas formation.

Keywords: platelet-rich plasma, regenerative cytokines, polypropylene mesh implant, periprosthetic fibrosis, seroma, puncture.

DOI: $10.21303 / 2504-5679.2019 .00957$

\section{Introduction}

Postoperative ventral hernias are a significant problem of modern surgery due to its wide prevalence, including among people of working age $[1,2]$. Thus, the choice of the optimal treatment tactics is extremely important in order to prevent possible postoperative complications [3, 4] and, in particular, reduce the duration of the rehabilitation period, which requires a multi-component integrated approach. Outside the discussion, there remains the question of using a mesh implant as a factor that significantly reduces the risk of hernia recurrence in comparison with outdated autoplastic techniques [3-6]. However, in spite of the wide range of materials offered for mesh implants, manufacturers still fail to achieve absolute biocompatibility [5, 7]. Polypropylene can be attributed to the most optimal of the available implant materials due to its high biological inertness $[4,8]$. An operative trauma and the presence of an implant in a wound initiate a local inflammatory process. It is also likely that nonspecific inflammatory reactions of the type "reactions to a foreign body" will develop, impeding optimal implant integration in the tissues, which in turn may lead to the development of postoperative complications $[1-3,7,8]$. In the early postoperative period, a prolonged alterative phase of inflammation in the tissues in contact with the prosthesis explains excessive exudation in the area of the alloplasty, which leads to the formation of seromas. Seroma are the most frequent complications of surgery of the hernia of the anterior abdominal wall and are found according to different authors in a wide range from $4 \%$ to $60 \%[1,3,7]$. In turn, the presence of seroma serves as a predictor of local infectious complications, such as suppuration and implant rejection, necrosis of the adipodermal flap [3, 4].

The problem of such early postoperative complications in herniology as the formation of fluid clusters was studied in the works of many authors, most of whom investigated mainly non-modifiable risk factors. At the moment there are no convincing data in the literature, and there are no unified proven approaches in reducing the risks of developing seromas by modifying surgical techniques or risk factors. Perioperative echoscopy (ultrasound) in the area of allohernioplasty all was stated as mandatory by authors. The indications for active drainage and its duration remain debatable. Risk factors include: violation of the local blood supply to the adipodermal flap due to significant mobilization from aponeurosis, separation of the structures of the anterior abdominal wall, overweight, choice of surgical techniques for tissue dissection, the presence of other foreign materials in tissues, smoking, the presence of concomitant somatic pathology $[3,6]$. The frequency of seromas development is repeatedly statistically proved with the choice of alloplasty technique: a significant increase in probability when the grid is in direct contact with subcutaneous fatty tissue (onlay, inlay, sandwich plastics options) due to constant contact and trauma of the tissue of the movable graft implant $[9,10]$. Seroma (lymphocele) can be diagnosed clinically by ultrasound (US), according to which it is possible to assess the presence, volume, depth, and partially the nature of the liquid contents. Also under the control of ultrasound, the fine needle aspiration puncture is optimally performed, which minimizes risks and also allows you to monitor the completeness of the procedure [7, 11]. The lack of control over the seroma in the area of allohernioplasty leads to the formation of lymphocele, an increase in the risk of local infectious complications, as well as an enormous increase in the risks of implant rejection [12, 13]. The factors of seroma prophylaxis available to the surgeon include choosing the optimal extent and technique of surgical intervention, 
inert implant and suture material, active drainage of the cavity over the prosthesis, local compression due to wearing abdominal bandage, postoperative ultrasound examination [13, 14]. In order to optimize regenerative reparative processes, it is locally advisable to use platelet-rich plasma (PRP) products as a donor of regenerative cytokines and matrix proteins $[15,16]$. It has been repeatedly proven that such a substrate stimulates regenerative processes, including through the accelerated flow of the alterative phase of local inflammation, which is expected to have a positive effect, minimizing the amount of exudate, reducing the frequency and severity of seromas.

\section{Aim of research}

Through the use of plasma enriched with platelets, reduce the severity of early postoperative complications in patients with postoperative ventral hernias.

\section{Materials and methods}

The study included 84 patients operated on for postoperative ventral hernias in the surgical department of the Center for reconstructive and restorative medicine (University Hospital) of the Odessa National Medical University from 2014 to 2018. The average age of patients is $58 \pm 5.3$ years. Gender distribution: men - 36, women - 48. Patients were divided into 2 groups: 1 - main (MG) $\mathrm{n}=40$ - patients with a standard volume of surgery - hernia repair, allohernioplasty of the anterior abdominal wall, in contrast to the control one was supplemented with local infiltration of soft tissues in the area of alloplasty with autologous PRP, 2 - control group (CG) - 44 patients who underwent exclusively allohernioplasty in a standard extent. The patients of the main study group were informed about the technique of material sampling, harvesting and also the introduction of PRP about which in each case writing informed consent was obtained. The research plan was agreed upon as a fragment of the dissertation work, the findings of the Commission on Bioethics of the Odessa National Medical University No. 120D dated October 30, 2017 was received. All patients were hospitalized and operated in a planned manner, at the preoperative stage they were examined in the required volume: laboratory tests, X-ray examination of chest, ECG, echocardioscopy, spirometry, consultations of related specialists. In 38 cases, a visualization study (MRT, CT) of the structures of the anterior abdominal wall and abdominal cavity was performed to assess the state of the supporting and muscular structures, select plastics, and exclude another significant abdominal pathology in the presence of an ambiguous clinical picture. In each case, at the preoperative stage, a diagnosis was formulated, which in $15 \%$ of cases was changed intraoperatively due to the presence of subclinical hernial defects. To characterize the hernial protrusion, the SWR classification of the European Herniology Association was used (EHS, J. Chevrel, A. Rath 1999). S - denotes hernia localization: median - M, lateral - L and combined - ML; W - width of the hernia gate: W1 - up to $5 \mathrm{~cm}, \mathrm{~W} 2$ 5-10 cm, W3 - 10-15 cm, W4 - over $15 \mathrm{~cm}$; R - the presence of relapse; R0, R1, R2 and more. The structure of the distribution of patients according to the hernia classification is presented in Table $\mathbf{1}$.

Table 1

The distribution of patients according to localization, size of the defect, relapse (EHS, J. Chevrel, A. Rath 1999)

\begin{tabular}{ccc}
\hline Indicator & $\begin{array}{c}\text { Main group } \\
(\mathbf{n = 4 0 )}\end{array}$ & $\begin{array}{c}\text { Control group } \\
(\mathbf{n}=\mathbf{4 4})\end{array}$ \\
\hline $\begin{array}{c}\text { Defect location: } \\
\text { M+ML (median and combined)/L (lateral) }\end{array}$ & $36 / 4$ & $3 / 7$ \\
Width of the defect & $90 \% / 10 \%$ & $84 \% / 16 \%$ \\
W1 $(<5 \mathrm{~cm}) / \mathrm{W} 2(5-10 \mathrm{~cm}) / \mathrm{W} 3(>10 \mathrm{~cm})$ & $13 / 23 / 4$ & $14 / 27 / 3$ \\
Relapses & $32 \% / 58 \% / 10 \%$ & $32 \% / 61 \% / 7 \%$ \\
R0/R1/R2+ & $29 / 7 / 4$ & $32 / 8 / 4$ \\
& $73 \% / 17 \% / 10 \%$ & $72 \% / 18 \% / 10 \%$
\end{tabular}

A significant risk factor is the presence of overweight [17, 18], in our sample the majority (78\% of the main and $74 \%$ of the control group) patients were obese. The average body mass 
index (BMI) in the main group was $31.2 \mathrm{~kg} / \mathrm{m}^{2}$, in the control group $32.5 \mathrm{~kg} / \mathrm{m}^{2}$. In the process of additional examination of patients, the following comorbidities were revealed, shown in Table 2.

Table 2

Gender ratio, body mass index, the presence of comorbidity in patients of the studied groups

\begin{tabular}{ccc}
\hline Criterion/Study group & Main group & Control group \\
\hline Number of patients & 40 & 44 \\
Gender F ratio & $17 / 23$ & $19 / 25$ \\
Average age & $61.2 \pm 6.7$ & $58.7 \pm 7.2$ \\
BMI average $\mathrm{kg} / \mathrm{m}^{2}$ & $31.2 \pm 6.4$ & $32.5 \pm 7.2$ \\
Obese patients (BMI> $\left.25 \mathrm{~kg} / \mathrm{m}^{2}\right)$ & $31(78 \%)$ & $33(74 \%)$ \\
Concomitant sub- and & $18(45 \%)$ & $16(36 \%)$ \\
decompensated pathology & & $11(25 \%)$
\end{tabular}

Patients with a hernial defect W3 were prevented from carrying out the compartment of the syndrome by wearing the abdominal band for at least 14 days. The study group did not include patients previously operated on for malignant neoplasms due to the discrepancy of some aspects of the use of PRP products in such patients and patients with a septic focus. Another exclusionary criterion was the addition of allohernioplasty with an abdominoplasty in order to reduce the heterogeneity of the study groups. In our opinion, such patients in this aspect should be considered as an isolated group. Also, patients who underwent laparoscopic alloplasty were not included in the study.

Before the induction of anesthesia, intraoperative patients from the main study group underwent blood sampling in prepared syringes with ACD-A anticoagulant, which later acted as containers for centrifugation, alternate layer-by-layer selection of a plasma layer with a buffer layer from all syringes, followed by centrifugation. By concentrating PRP in the lower third of the volume, it was possible to obtain a PRP substrate in a significant amount (up to $38 \mathrm{ml}$ ) with all the requirements for quantitative concentration, if the technology is observed, the substrate is aseptic and applicable intraoperatively. Such a modified DoubleSpin technique allows you to get a significant amount of substrate in comparison with the proposed analogues and has significant economic advantages. PRP activation was carried out with a $10 \% \mathrm{CaCl}_{2}$ solution in a ratio of 1:10 10 minutes before use. In all cases, hernia repair was performed with tissue separation by monopolar coagulation, as well as using the EC 300M1 bipolar dissector (Patonmed, Ukraine) in the welding mode. Allohernioplasty of the structures of the anterior abdominal wall was performed using the mesh lightweight $\left(80 \mathrm{~g} / \mathrm{m}^{2}\right)$ Prolene polypropylene implant (Ethicon, USA). In all cases, the choice of the method of plastic surgery was considered individually intraoperatively based on the size, localization, condition of the anterior abdominal wall supporting layers, the severity of subcutaneous fatty tissue, and the severity of the patient's condition, taking into account anaesthetic risks. The distribution of patients according to the nature of the plastic is shown in Tab. 3. In all cases, alloplasty can be considered as non-tensioned. The preference was given to the implementation of the "SubLay" technique with hernia defects of small size, this group included patients who had variants of components of separation plastic, as well as Ramires plastic with large hernias.

These patients were combined into a subgroup "SubLay + TAR" Table 3. In other cases, with extensive defects and the presence of concomitant pathology, preference was given to "OnLay" plastics as well as variants of the so-called "Sandwich" plastics with forced placement of the upper layer of the mesh implant in direct contact with the subcutaneous fatty tissue. Such patients were grouped into the "OnLay + Sandwich" subgroup (Table 3). The criteria: contact of the mesh with subcutaneous fatty tissue, as well as a large area of dissection of fatty tissue from aponeurosis, were crucial in uniting patients who underwent such interventions into a single group. 
Table 3

The distribution of patients by the nature of plastic

\begin{tabular}{ccc}
\hline Criterion/Study group & $\begin{array}{c}\text { Main group } \\
(\mathbf{n}=\mathbf{4 0 )}\end{array}$ & $\begin{array}{c}\text { Control group } \\
(\mathbf{n}=\mathbf{4 4})\end{array}$ \\
\hline "SubLay"+TAR & $24(60 \%)$ & $27(61 \%)$ \\
"OnLay"+ "Sandwich" & $16(40 \%)$ & $17(39 \%)$
\end{tabular}

In all cases, the size of the implant was determined taking into account the overlap on the supporting layers of the abdominal wall with an indent of about $3 \mathrm{~cm}$ from the edge of the hernia gate. Mesh fixation was performed around the perimeter with a Prolene 0/1-0 thread.

In patients of the main group, local injection of liquid plasma substrate enriched with platelets was performed by puncture infiltration of soft tissues in contact with the prosthesis. More controlled administration due to dosing and safety was achieved using a $13 \times 0.3 \mathrm{~mm}$ needle. Thus, the risk of injury to the underlying intestinal vascular structures was significantly reduced. In the process of infiltration, preference was given to fatty structures in view of the presence of mesenchymal stem cells in them, which serve as a target for regenerative cytokines infused with PRP. This type of injection makes it possible to evenly distribute the PRP volume over a significant surface area of contact with the implant and also the surface of the free adipodermal flap over the entire dissection surface. According to observations, this procedure took from 4 to 13 minutes. The adipodermal flap was not fixed to the underlying structures of the abdominal wall due to the inconsistency of data from various authors on the risks and effectiveness of this technique.

In the overwhelming majority of cases, the space above the mesh prosthesis remained unified and drained by silicone drainage with a diameter of $6 \mathrm{~mm}$ and a longitudinal section (Kammed, Ukraine) was active along Redon, into a volume of 200-600 $\mathrm{ml}$ with a pressure of $98000 \mathrm{~Pa}$. Drainage was not performed in the case of "SubLay" plastics with W1 hernial defects. Drainage was maintained in the wound from 2 to 5 days, as it was proved that a longer drainage significantly increases the risk of septic complications. Another criterion for the removal of drainage was a decrease in the volume of discharge to $30 \mathrm{ml}$ per day. After removal of the drainage, local control of the serous discharge in the plastic zone was carried out by regularly performing ultrasound monitoring (EsaoteMyLab 20 plusUltrasoundSystem, linear sensor) with a frequency of 4 to 7 days, according to which the presence and amount of the discharge was monitored with single-step control of fine needle aspiration puncture in order to achieve completeness of aspiration, as well as to ensure the safety of the procedure. The approximate volume of seroma was determined by direct linear measurement of the maximum size of seroma in three projections, taking into account the coefficient $-k$.

$$
V(\mathrm{ml})=k \times A \times B \times C,
$$

where $A, B, C$ linear dimensions of the cluster (cm), $k$ - coefficient with a fixed value $=0.52$ [19].

The criterion of puncture aspiration was selected volume of more than $30 \mathrm{ml}$ for a period of less than 4 days from the time of the previous puncture. With a smaller volume in the overwhelming majority of our observations, a regression of fluid accumulation was observed, requiring a one-time control ultrasound after 2 weeks. The volume of fluid accumulations was determined over a period of up to 3 months in some cases, however, the first 28 days can be considered as the most indicative; it is observation period that is presented in the graphs (Fig. 1). Postoperative management of all patients included selective adherence to the principles of FastTrackSurgery early activation and independent walking no later than 12 hours after the intervention. Patients during the first day began receiving enteral nutrition. All patients were recommended to wear an abdominal band up to 6 weeks after surgery. The mode of antibiotic prophylaxis, antibiotic therapy, prevention of thromboembolic complications, the nature of nutrition were the same in both 
groups of patients. In accordance with the somatic status, the nature of the hernial protrusion, as well as the option of plastics, preference was given to antibiotic prophylaxis for somatically preserved patients with smaller hernial defects. In other cases, resorted to antibiotic therapy. Pain control was carried out at the request of the patient himself by the introduction of NSAIDs (dexketoprofen $50 \mathrm{mg}$ ), and discomfort when taking a deep breath was identified as a signal for pain relief. The severity of pain syndrome was calculated by the total number of analgesic injections that were required during the first 3 postoperative days. In the postoperative period, after 2 hours, after 12 hours, on days 3 and 7 of the postoperative day, the degree of pain syndrome was evaluated on the VAS scale.

Comparative criteria for the early postoperative period were determined: the severity of pain, the presence of complications, the amount of serous discharge in terms of daily flow rate, length of stay in hospital, rehabilitation time, taking into account the number, frequency and total duration of aspiration puncture for fluid clusters.

Statistical analysis was performed using standard and modified https://docs.google.com algorithms. To compare the dynamics of the flow rate of the discharge in the studied groups, a non-parametric index — the Pearson $\chi^{2}$ coefficient - was used; to study the dynamics, the indicators of the study of dynamic series were used. Static comparison parameters: the estimated value of the degree of freedom $=1$; at $\mathrm{p}$-level $<0.05 \chi^{2}=3.84$; with $\mathrm{p}<0.01 \%, \chi^{2}=6.63$. Non-parametric criteria can not be traced.

\section{Results}

Evaluation of the results of treatment was carried out with the separation of patients of the main and control groups on the basis of the transferred volume of allohernioplasty. 1 - the main group - patients with which the extent of surgical intervention was supplemented by local infiltration of the implantation zone of the autologous PRP prosthesis. 2 - the control group is as similar in structure as possible, in which the patients received only a standard amount of surgical intervention. Each of the groups, in turn, was divided into 2 subgroups, taking into account the nature of allohernioplasty: with the contact of the mesh prosthesis with the structures of the subcutaneous fatty tissue and with the location of the mesh implant out of contact with the subcutaneous fatty tissue. The distribution of groups by size, localization of the hernial defect and the average body mass index are presented in Table 1, 2, these data characterize a fairly high level of homogeneity in the comparison groups.

In the main study group, at the stage of additional examination of all patients, the determination of the level of platelets in the blood was performed, as well as in order to monitor the compliance of PRP with the requirements of determining the level of substrate platelets. The data of the average ratio of the number of PRP platelets to the original level of whole blood platelets in each of the subgroups of the main study are given in Table 4.

Table 4

Demonstration of the platelet count of whole blood and platelet count in PRP

\begin{tabular}{|c|c|}
\hline \multicolumn{2}{|c|}{ Blood plasma } \\
\hline Studied patients average platelet count & $40(100 \%), 307 \pm 56 \times 10^{9} / 1$ \\
\hline \multicolumn{2}{|c|}{ Platelet rich plasma (PRP) } \\
\hline Studied patients average platelet count & $34(85 \%), 1073 \pm 106 \times 10^{9} / 1$ \\
\hline
\end{tabular}

The multiplication factor of the number of platelets in PRP in comparison with the original number $=3.5 \times$

Comparison of the amount of analgesic injections (Dexketoprofen $50 \mathrm{mg}$ ) required for sufficient pain relief when paired comparison of the main group and the control group (Table 5).

Data on pain scores are given on a Visually analogue scale after surgery after 2 hours, after 12 hours, on days 3 and 7 of the postoperative day s shown (Table 6). 
Table 5

The level of pain in comparing the subgroups of the main and control groups, the number of injections of NSAIDs

\begin{tabular}{lcc}
\hline \multicolumn{1}{c}{ Criterion/Study group } & $\begin{array}{c}\text { Main group } \\
(\mathbf{n}=\mathbf{4 0 )}\end{array}$ & $\begin{array}{c}\text { Control group } \\
(\mathbf{n}=\mathbf{4 4 )}\end{array}$ \\
\hline $\begin{array}{l}\text { Number of Dexketoprofen injections 50mg in 1 day, average } \\
\begin{array}{l}\text { The total number of injections of Dexketoprofen } 50 \mathrm{mg} \text { during the } \\
\text { postoperative period in the hospital, average }\end{array}\end{array}$ & $2.2 \pm 0.6$ & $2.6 \pm 0.4$ \\
\end{tabular}

Table 6

Pain intensity assessment according to the Visually Analogue Scale (VAS), $\mathrm{p}>0.005$

\begin{tabular}{ccc}
\hline \multirow{2}{*}{ Observation period } & \multicolumn{1}{c}{ The severity of pain syndrome (Me) } \\
\cline { 2 - 3 } & $\begin{array}{c}\text { Main group } \\
(\mathbf{n}=\mathbf{4 0 )}\end{array}$ & $\begin{array}{c}\text { Control group } \\
(\mathbf{n}=\mathbf{4 4})\end{array}$ \\
\hline 2 hours & $67 \pm 7.2$ & $71 \pm 7.6$ \\
24 hours & $41 \pm 5.3$ & $43 \pm 6.6$ \\
3 days & $21 \pm 4.8$ & $19 \pm 3.6$ \\
7 days & $13 \pm 2.6$ & $15 \pm 2.2$
\end{tabular}

The results show an identical level of pain in the subgroups compared in pairs. Of course, this criterion does not apply to the standard in measuring the level of postoperative pain, but in our opinion may indirectly show the absence of significant changes in the level of pain in the postoperative period. Other painkillers were not used. According to VAS, there was a tendency to a decrease in the intensity of pain syndrome in the early postoperative period in patients of the main study group.

The complications in each of the studied groups were analyzed (Table 7). These data demonstrate the absence of significant infectious, pyrogenic, allergic postoperative complications, which may indicate sufficient safety and full biological compatibility of PRP obtained by the proposed technology.

Table 7

Quantitative assessment of the recorded postoperative complications in isolation in each of the studied groups

\begin{tabular}{cccc}
\hline Criterion/Study group & $\begin{array}{c}\text { Main group } \\
(\mathbf{n = 4 0 )}\end{array}$ & $\begin{array}{c}\text { Control group } \\
(\mathbf{n = 4 4 )}\end{array}$ & Validity criterion p \\
\hline Hematoma in the area of allohernioplasty & $1(2.5 \pm 0.3 \%)$ & $2(4.5 \pm 0.6 \%)$ & $\mathrm{p}=0.014$ \\
Infiltration in the area of allohernioplasty & $2(5 \pm 0.6 \%)$ & $2(4.5 \pm 0.6 \%)$ & $\mathrm{p}=0.23$ \\
Regional necrosis of the skin & $2(5 \pm 0.6 \%)$ & $4(9.1 \pm 1.1 \%)$ & $\mathrm{p}=0.009$ \\
Hernia recurrence (over the observation period) & $1(2.5 \pm 0.3 \%)$ & $2(4.5 \pm 0.6 \%)$ & $\mathrm{p}=0.009$
\end{tabular}

The quantitative and visual assessment of fluid accumulations in the allohernioplasty zone is shown in the graph showing the average volume of discharge in each of the studied groups, according to the recording of discharge volume by active drainage system, ultrasound data on the volume of fluid accumulations, as well as recording the volume after performing aspiration punctures (Fig. 1). The presented data demonstrate a significant decrease in the volume of fluid accumulations in the main study group compared with the control group. Significant differences are observed from the first day of observation. Quantitatively, the trend persists, the differences are recorded throughout the study with the strengthening of statistically significant differences. 


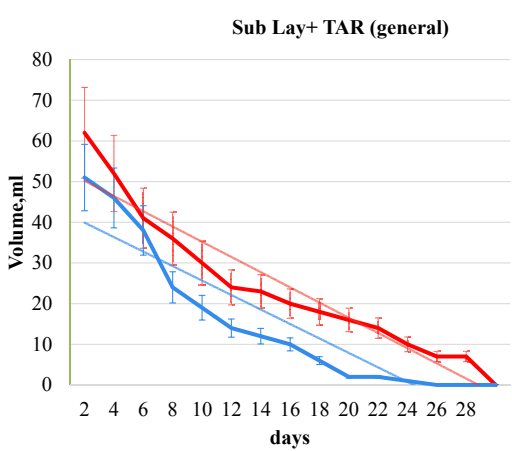

$a$

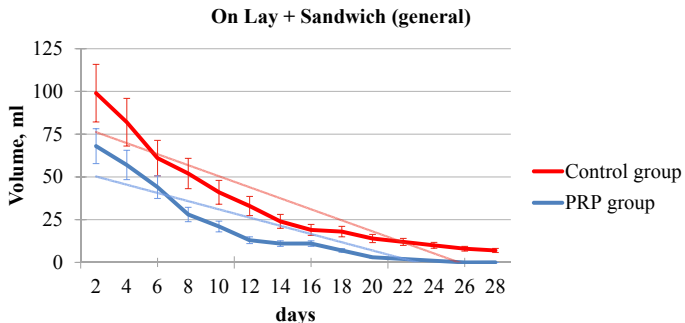

$c$
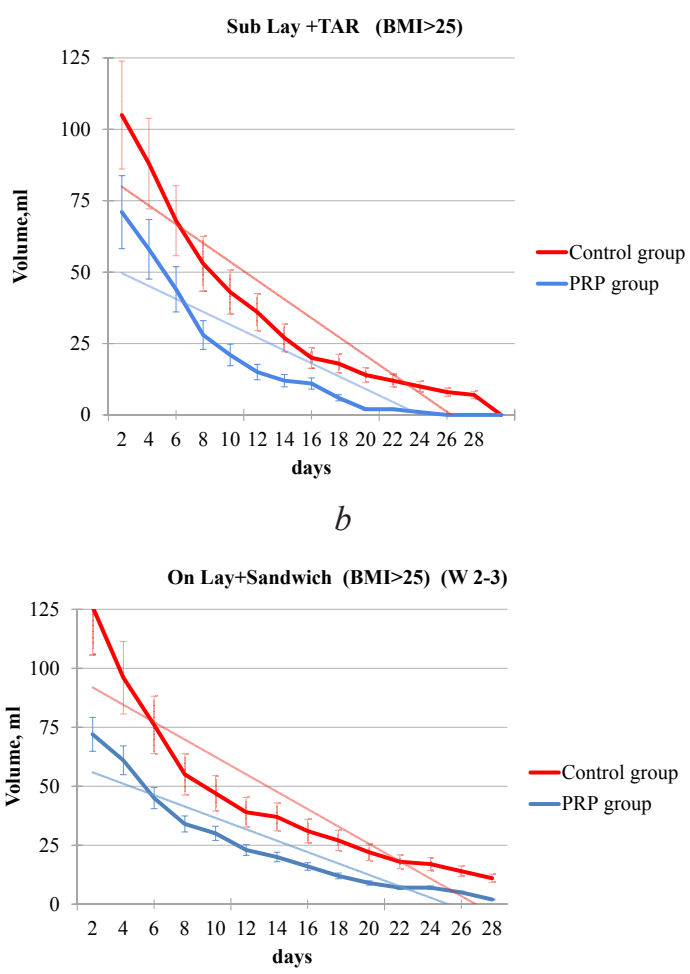

$d$

Fig. 1. The average volume of fluid accumulations ( $\mathrm{ml} /$ day) in each of the studied groups according to the given selection criteria (nature of plastics, BMI), observation over time, daily counting: $a$ - SubLay + TAR group (total); $b$ - SubLay + TAR group (in patients with obesity); $c$ - group OnLay + Sandwich (general); $d$ - group OnLay + Sandwich (in patients with obesity))

\section{Discussion}

After evaluating the postoperative complications in the main study and control groups, it can be argued that the proposed technique of infiltration of the autologous PRP to prosthesis implantation zone carries no additional risks in comparison with the control group, as demonstrated, respectively, by the minimum number of complications. Assessing quantitatively the complications in the main and control groups, identical indicators were obtained, demonstrating the absence of additional risks of the proposed technique. Pain in the early postoperative period in the main study group compared with the control group does not have significant statistical deviations according to the VAS score. The effectiveness of the above method in reducing the severity of fluid accumulations in the area of allohernioplasty is observed in almost all groups in comparison with the control ones. Statistically, the reliability, as well as the quantitative difference in values, increases when compared in groups with a larger size of the hernial defect, and accordingly with a larger area of the used prosthesis with the same technique of plastics. Significantly more differences were in the group of patients operated on by the method "OnLay", "Sandwich". In turn, the quantitative difference in values is higher in the group of obese patients of 2-3 degrees.

Thus, after statistical analysis, it was established that the severity of such early postoperative complications as the presence of fluid accumulations in the alloplasty zone, according to our data, confirms the dependence on well-known risk factors. These include: overweight, the presence of sub- and decompensated comorbidity, the nature of plastics, namely, the fact that the prosthesis is in contact with the subcutaneous fatty tissue and the width of the tissue dissection, the size of the prosthesis. Unfortunately, in our study, the plasma marker IL-1RA was not taken into account, as a specific indicator proved to be an increased risk of seromas formation [20].

The obtained data correspond to previously published data and demonstrate the relationship of the degree of severity of postoperative seromas in accordance with the presence of risk factors 
for obesity, as well as depending on the choice of allohernioplasty technique. The correlation between the body mass index and the frequency and severity of seromas was given earlier [20, 21]. Many authors have stated the connection between the choice of alloplasty technique and the degree of severity of fluid clusters $[20,22]$. A key aspect can be considered the fact of contact of the mesh prosthesis with subcutaneous fatty tissue, as a factor that significantly increases the risk of early postoperative complications [23].

Thus, the proposed method of infiltration of the implantation zone of a prosthesis with autologous platelet-rich plasma is safe and effective for the purpose of preventing such early postoperative complications as fluid accumulations - seromas.

The limitations of the study should include the observation time limited to 1 month.

\section{Conclusions}

1. The risk of development and the severity of fluid accumulations in the area of allohernioplasty can be predicted taking into account such risk factors as the size of the hernial defect, the nature of plastics, the presence of concomitant pathology, overweight.

2. Technique of infiltration of soft tissues in contact with a polypropylene prosthesis is safe, without significantly increasing the risk of local or systemic complications.

3. The proposed method significantly reduces the risk of development and the severity of fluid accumulations in the area of implantation of the prosthesis.

4. The effectiveness of the technique is significantly higher compared to groups of patients with a high risk of seromas formation.

\section{References}

[1] Le Huu Nho, R., Mege, D., Ouaïssi, M., Sielezneff, I., Sastre, B. (2012). Incidence and prevention of ventral incisional hernia. Journal of Visceral Surgery, 149 (5), 3-14. doi: http://doi.org/10.1016/j.jviscsurg.2012.05.004

[2] Dietz, U. A., Winkler, M. S., Härtel, R. W., Fleischhacker, A., Wiegering, A., Isbert, C. et. al. (2012). Importance of recurrence rating, morphology, hernial gap size, and risk factors in ventral and incisional hernia classification. Hernia, 18 (1), $19-30$. doi: http://doi.org/10.1007/s10029-012-0999-x

[3] Golovin, R. V., Nikitin, N. A., Prokopev, E. S. (2014). Prognozirovanie razvitiia ranevykh oslozhnenii posle kombinirovannoi allogernioplastiki pri posleoperatsionnykh ventralnykh gryzhakh sredinnoi lokalizatsii. Sovremennye Problemy nauki i obrazovaniia, 2. Available at: https://www.science-education.ru/ru/article/view?id=12914

[4] Vlasov, A. V., Kukosh, M. V. (2013). Problema ranevykh oslozhnenii pri endoprotezirovanii briushnoi stenki po povodu ventralnykh gryzh. Sovremennye tekhnologii v meditsine, 5 (2), 116-124.

[5] Mikhin, I. V., Kukhtenko, Iu. V., Panchishkin, A. S. (2014). Bolshie i gigantskie posleoperatsionnye ventralnye gryzhi: vozmozhnosti khirurgicheskogo lecheniia (obzor literatury). Vestnik Volgogradskogo gosudarstvennogo meditsinskogo universiteta, 2, 8-16.

[6] Charyshkin, A. L., Frolov, A. A. (2015). Problemy gernioplastiki u bolnykh s posleoperatsionnymi ventralnymi gryzhami. Ulianovskii mediko-biologicheskii zhurnal, 2, 40-47.

[7] Amid, P. K. (1997). Classification of biomaterials and their related complications in abdominal wall hernia surgery. Hernia, 1 (1), 15-21. doi: http://doi.org/10.1007/bf02426382

[8] Ghazi, B., Deigni, O., Yezhelyev, M., Losken, A. (2011). Current Options in the Management of Complex Abdominal Wall Defects. Annals of Plastic Surgery, 66 (5), 488-492. doi: http://doi.org/10.1097/sap.0b013e31820d18db

[9] Plymale, M. A., Harris, J. W., Davenport, D. L., Smith, N., Levy, S., Scott, R. J. (2016). Abdominal Wall Reconstruction: the uncertainty of the impact of drain duration upon outcomes. The American Surgeon, 82 (3), 207-211.

[10] Westphalen, A. P., Araújo, A. C. F., Zacharias, P., Rodrigues, E. S., Fracaro, G. B., Lopes Filho, G. de J. (2015). Repair of large incisional hernias. To drain or not to drain. Randomized clinical trial. Acta Cirurgica Brasileira, 30 (12), 844-851. doi: http:// doi.org/10.1590/s0102-865020150120000009

[11] Postnikov, D. G., Pavlenko, V. V., Oorzhak, O. V., Lesnikov, S. M., Krasnov, O. A., Egorova, O. N., Salimov, V. R. (2014). Sravnitelnyi analiz rezultatov profilaktiki ranevykh oslozhnenii pri gernioplastike posleoperatsionnykh gryzh. Meditsina i Obrazovanie v Sibiri, 6. Available at: http://ngmu.ru/cozo/mos/article/pdf.php?id=1621

[12] Bercial, M. E., Sabino Neto, M., Calil, J. A., Rossetto, L. A., Ferreira, L. M. (2011). Suction Drains, Quilting Sutures, and Fibrin Sealant in the Prevention of Seroma Formation in Abdominoplasty: Which is the Best Strategy? Aesthetic Plastic Surgery, 36 (2), 370-373. doi: http://doi.org/10.1007/s00266-011-9807-8 
[13] Swanson, E. (2015). Seroma Prevention in Abdominoplasty: Eliminating the Cause. Aesthetic Surgery Journal, 36 (1), NP23NP24. doi: http://doi.org/10.1093/asj/sjv121

[14] Sforza, M., Husein, R., Andjelkov, K., Rozental-Fernandes, P. C., Zaccheddu, R., Jovanovic, M. (2015). Use of Quilting Sutures During Abdominoplasty to Prevent Seroma Formation: Are They Really Effective? Aesthetic Surgery Journal, 35 (5), 574-580. doi: http://doi.org/10.1093/asj/sju103

[15] Alsousou, J., Ali, A., Willett, K., Harrison, P. (2012). The role of platelet-rich plasma in tissue regeneration. Platelets, 24 (3), 173-182. doi: http://doi.org/10.3109/09537104.2012.684730

[16] Fernandez-Moure, J. S., Van Eps, J. L., Menn, Z. K., Cabrera, F. J., Tasciotti, E., Weiner, B. K., Ellsworth, W. A. (2015). Platelet rich plasma enhances tissue incorporation of biologic mesh. Journal of Surgical Research, 199 (2), 412-419. doi: http://doi. org/10.1016/j.jss.2015.06.034

[17] Nasr, M. W., Jabbour, S. F., Mhawej, R. I., Elkhoury, J. S., Sleilati, F. H. (2016). Effect of Tissue Adhesives on Seroma Incidence After Abdominoplasty: A Systematic Review and Meta-Analysis. Aesthetic Surgery Journal, 36 (4), $450-458$. doi: http://doi.org/10.1093/asj/sjv276

[18] Nockolds, C. L., Hodde, J. P., Rooney, P. S. (2014). Abdominal wall reconstruction with components separation and mesh reinforcement in complex hernia repair. BMC Surgery, 14 (1). doi: http://doi.org/10.1186/1471-2482-14-25

[19] Dicuio, M., Pomara, G., Menchini, F. F., Ales, V., Dahlstrand, C., Morelli, G. (2005). Measurements of urinary bladder volume: comparison of five ultrasound calculation methods in volunteers. The Archives of Italian Urology and Andrology, 77 (1), 60-62.

[20] Klink, C. D., Binnebösel, M., Lucas, A. H., Schachtrupp, A., Grommes, J., Conze, J. et. al. (2010). Serum analyses for protein, albumin and IL-1-RA serve as reliable predictors for seroma formation after incisional hernia repair. Hernia, 15 (1), 69-73. doi: http://doi.org/10.1007/s10029-010-0746-0

[21] Sonis, A. G., Grachev, B. D., Stoliarov, E. A., Ishutov, I. V. (2014). Profilaktika i lechenie infektsionnykh ranevykh oslozhnenii pri proteziruiushhikh gryzhesecheniiakh. Rany i Ranevaia Infektsiia, 2, 16-22.

[22] Kosins, A. M., Scholz, T., Cetinkaya, M., Evans, G. R. D. (2013). Evidence-based value of subcutaneous surgical wound drainage: the largest systematic review and meta-analysis. Plastic and Reconstructive Surgery, 132 (2), 443-450. doi: http:// doi.org/10.1097/prs.0b013e3182958945

[23] Postnikov, D. G., Pavlenko, V. V., Krasnov, O. A., Oorzhak, O. V., Egorova, O. N., Lesnikov, S. M. (2015). Problemy profilaktiki ranevykh oslozhnenii u bolnykh s posleoperatsionnymi ventralnymi gryzhami. Meditsina i Obrazovanie v Sibiri, 3. Available at: https://cyberleninka.ru/article/v/problemy-profilaktiki-ranevyh-oslozhneniy-u-bolnyh-s-posleoperatsionnymi-ventralnymigryzhami 